\title{
Article \\ Precipitation Behaviors of Carbides in High Speed Steel during ESR and Heat Treatment
}

\author{
Yang Liu ${ }^{1}$, Jing $\mathrm{Li}^{1}{ }^{1} *$, Wei Liang ${ }^{1}$, Jiawei Gao ${ }^{1}$, Yongfeng $\mathrm{Qi}^{1}$ and Chengjia Shang ${ }^{2}$ \\ 1 State Key Laboratory of Advanced Metallurgy, University of Science and Technology Beijing, \\ Beijing 100083, China; b20170516@xs.ustb.edu.cn (Y.L.); b20200579@xs.ustb.edu.cn (W.L.); \\ g20199335@xs.ustb.edu.cn (J.G.); d202110628@xs.ustb.edu.cn (Y.Q.) \\ 2 Yangjiang Branch, Guangdong Laboratory for Materials Science and Technology (Yangjiang Advanced Alloys \\ Laboratory), Yangjiang 529500, China; cjshang@ustb.edu.cn \\ * Correspondence: lijing@ustb.edu.cn; Tel.: +86-189-1108-2675
}

Citation: Liu, Y.; Li, J.; Liang, W.; Gao, J.; Qi, Y.; Shang, C. Precipitation Behaviors of Carbides in High Speed Steel during ESR and Heat Treatment. Metals 2021, 11, 1781. https://doi.org/ $10.3390 /$ met11111781

Academic Editor: Andrea Di Schino

Received: 28 September 2021

Accepted: 1 November 2021

Published: 5 November 2021

Publisher's Note: MDPI stays neutral with regard to jurisdictional claims in published maps and institutional affiliations.

Copyright: (c) 2021 by the authors. Licensee MDPI, Basel, Switzerland. This article is an open access article distributed under the terms and conditions of the Creative Commons Attribution (CC BY) license (https:/ / creativecommons.org/licenses/by/ $4.0 /)$.
Abstract: The microstructure and carbides evolution of high-speed steel after electroslag remelting and solution treatment were studied. The thermodynamic precipitation mechanism of carbides in solid phase was discussed and the characteristic parameters of carbides in different processes were also investigated. The results show that there were large lamellar and fibrous $\mathrm{Mo}_{2} \mathrm{C}$ and a small amount of VC in the ESR ingot. $\mathrm{Mo}_{2} \mathrm{C}$ are metastable carbides, which can be decomposed into VC and $\mathrm{Fe}_{2} \mathrm{Mo}_{4} \mathrm{C}$ during the solution treatment. The average diameter of the carbides is reduced to $1.28 \mu \mathrm{m}$ and the space distance is reduced to $3.23 \mu \mathrm{m}$ after forging and hot rolling, which means carbides are completely spheroidal and dispersed in matrix.

Keywords: electroslag remelting; carbide; high speed steel; solution treatment; microstructure

\section{Introduction}

High-speed steels (HSS) are widely used in making high-speed cutting tools, which always require high hardness, good wear resistance, and good thermal fatigue resistance at elevated temperatures [1,2]. This kind of wear-resistant and heat-resistant tool steel with secondary hardening characteristics contains a large amount of tungsten, molybdenum, vanadium, chromium, and other alloy elements [3-5].

It is well known that the type, morphology, size, and distribution of carbides have great influence on the mechanical properties of high-speed steel, which are closely related to the as-cast structure of ingots, especially eutectic carbides. $\mathrm{M}_{2} \mathrm{C}$ is a typical carbide in $\mathrm{W}$-Mo high speed steel [6]. $\mathrm{M}_{2} \mathrm{C}$ is easy to decompose into stable carbides with reaction $\mathrm{M}_{2} \mathrm{C}+\mathrm{Fe}(\gamma) \rightarrow \mathrm{M}_{6} \mathrm{C}+\mathrm{MC}$, therefore, it is easy to decompose when heated [7]. High speed steel contains a large amount of reticulated eutectic carbides, which are brittle and easy to crack during forging, which will cause serious segregation and affect its service performance [8]. It has been reported that the presence in carbide distribution of significant fraction of ultrafine particles can improve wear resistance of high-speed steel by 2.13 times compared with the conventional treatment while hardness increases by $7.76 \%$ and wear rate decreases [9-11]. It is significant to improve the morphology and distribution of eutectic carbides in high-speed steel.

The evolution of microstructure and carbides in high-speed steel is strongly influenced by the obtainment process. Ideally, depending on the application, some best mechanical properties are expected when the microstructure showed a homogeneous distribution of the carbides in the matrix, but the achievement of this microstructure is very difficult because the carbide formation occurs in several stages of the obtainment process. 
The electroslag remelting (ESR) process is usually used to improve the solidification structure, cleanliness, and transverse mechanical properties of high-speed steel $[12,13]$. It was reported that the consumable electrode and rotation of a mold, respectively, in ESR process can not only reduce the size and alleviate the segregation of carbides in HSS ingot, but also improve the surface quality of ingots and reduce inclusions [14,15]. However, the alloying elements are easy to segregate seriously and form large eutectic carbides in the manufacturing process, which is difficult to eliminate in the subsequent forging and other heat treatment processes [16]. Therefore, continuous directional solidification of electroslag remelting (ESR-CDS) is considered as a widely used secondary refining technology for producing high quality HSS. Li et al. [17] and Fu et al. [18] demonstrate that ESR-CDS could effectively eliminate macro-segregation in as-cast ingot through the shallow molten metal pool controlled by directional solidification.

The present work aims to study the effect of heat treatment and hot deformation on morphology, size, and distribution of carbides in high speed steel after ESR-CDS process. By improving process parameters, thick eutectic carbide can be eliminated, and carbide shape and product performance can be eventually improved.

\section{Materials and Methods}

Casted HSS used in the present study was melted with pure alloy ingredients in a vacuum induction furnace (Huairou, Beijing, China) with capacity of $50 \mathrm{~kg}$. The liquid steel was cast in a mold, and then forged into electrode with a diameter of $120 \mathrm{~mm}$. Then the electrode was electroslag remelted to produce ingot of $160 \mathrm{~mm}$ diameter through ESR-CDS. The remelting process was conducted in the atmosphere with blowing argon at the top of the crystallizer. The chemical composition of the steel is shown in Table 1.

Table 1. Chemical composition of steel ( $w \mathrm{t} \%)$.

\begin{tabular}{ccccccccc}
\hline $\mathbf{C}$ & W & Mo & Cr & V & Si & Mn & Y & Fe \\
\hline 1.2 & 3.5 & 8.2 & 3.9 & 2.8 & 0.62 & 0.3 & 0.03 & Bal. \\
\hline
\end{tabular}

The experimental process includes heat treatment, forging, and hot rolling. The ESR ingot was held at $1100{ }^{\circ} \mathrm{C}$ for $24 \mathrm{~h}$ and then forged to bars. The forging start temperatures were controlled in the range of $1060-1100{ }^{\circ} \mathrm{C}$ and the forging finish temperatures were controlled to be higher than $910{ }^{\circ} \mathrm{C}$ while the forging ratio was 4 . Thereafter, the steel was rolled into $\Phi 11 \mathrm{~mm}$ by rolling mill. The specimens of ESR ingot were subjected to the solution treatment at the temperatures of $1080{ }^{\circ} \mathrm{C}$ and $1130{ }^{\circ} \mathrm{C}$ for $1 \mathrm{~h}, 2 \mathrm{~h}$, and $4 \mathrm{~h}$. The scheme is shown in Table 2 and Figure 1. They were heat treated in an electric resistance furnace, and quenched in water.

Table 2. Solution treatment process.

\begin{tabular}{ccc}
\hline Specimen Number & Solution Treatment Temperature & Solution Treatment Time \\
\hline $1080-1$ & & $1 \mathrm{~h}$ \\
$1080-2$ & $1080{ }^{\circ} \mathrm{C}$ & $2 \mathrm{~h}$ \\
$1080-4$ & & $4 \mathrm{~h}$ \\
$1130-1$ & & $1 \mathrm{~h}$ \\
$1130-2$ & $1130{ }^{\circ} \mathrm{C}$ & $2 \mathrm{~h}$ \\
$1130-4$ & & $4 \mathrm{~h}$ \\
\hline
\end{tabular}



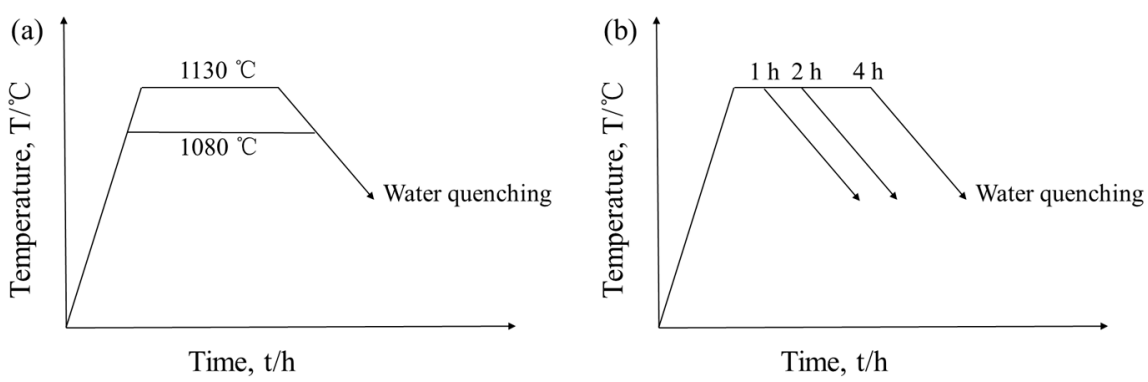

Figure 1. Experimental process for the solution treatment: (a) solution treatment temperature; (b) solution treatment time.

The samples with the dimension of $15 \mathrm{~mm} \times 15 \mathrm{~mm} \times 12 \mathrm{~mm}$ were taken from as-cast and ESR ingots, respectively. The microstructure of the samples was observed by optical microscope (Leica DM4M, Leica Microsystems, Wetzlar, Germany, OM), and carbides were characterized by scanning electron microscope (FEI MLA250, FEI, Hillsboro, OR, USA, SEM) equipped with energy-dispersive X-ray spectrometer (XFlash 5030, Bruker, Karlsruhe, Germany, EDS), after grinding, polishing, and etching with $4 \%$ nitric acid in alcohol. The chemistry of various precipitates identification at different temperatures and phase equilibrium investigation were calculated by Thermo-calc software (Thermo-calc Software Inc., Solna, Sweden). The samples taken from HSS were machined into a rod of $\varnothing 15 \mathrm{~mm} \times 90 \mathrm{~mm}$. Carbides were extracted from steel matrix in organic solution (methanol, tetramethylammonium chloride, glycerin, diethanol amine) by 90 . Some were analyzed by X-ray diffraction (Rigaku Dmax-RB, Rigaku, Tokyo, Japan, XRD) to confirm the types, and others were observed by SEM for the three-dimensional morphology.

\section{Results and Discussion}

\subsection{Microstructure of As-Cast and ESR Ingot}

The solidification structure and microstructure of as-cast and ESR ingot are shown in Figures 2 and 3, partial primary carbides precipitated along austenite grain boundaries and eutectic ledeburite formed network. The matrix structure in the HSS as-cast ingot was extremely uneven in both morphology and size. The primary and secondary dendrites were coarse, and some relatively coarse tertiary dendrites appeared. The eutectic ledeburite was in the shape of uneven flakes, and the segregation of the ingot was relatively serious. The structure obtained by the ESR-CDS process was relatively uniform and dense, mainly composed of fine dendrites. There was a large amount of white matrix around the eutectic ledeburite. The ledeburite was small, and some of which were short rods, which was more beneficial to the structure and performance of the material in the subsequent deformation processing process [19]. It can be obtained from the above analysis that the level of solidification and shrinkage greatly reduced after the ESR-CDS process.
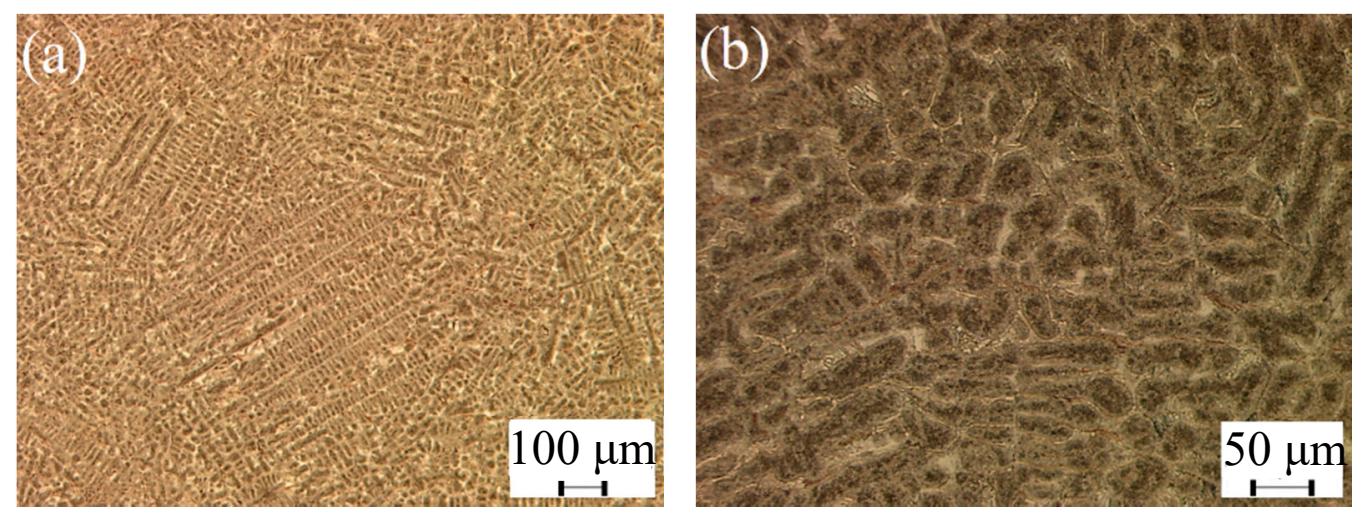

Figure 2. Cont. 

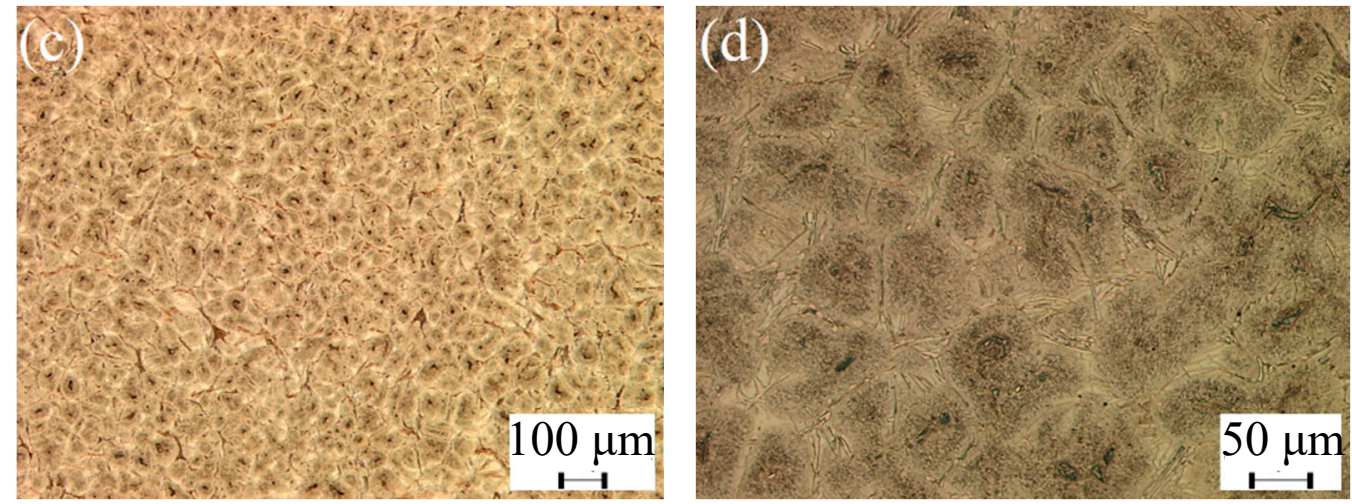

Figure 2. OM images of HSS solidification structure: (a,b) As-cast ingot; (c,d) ESR ingot.
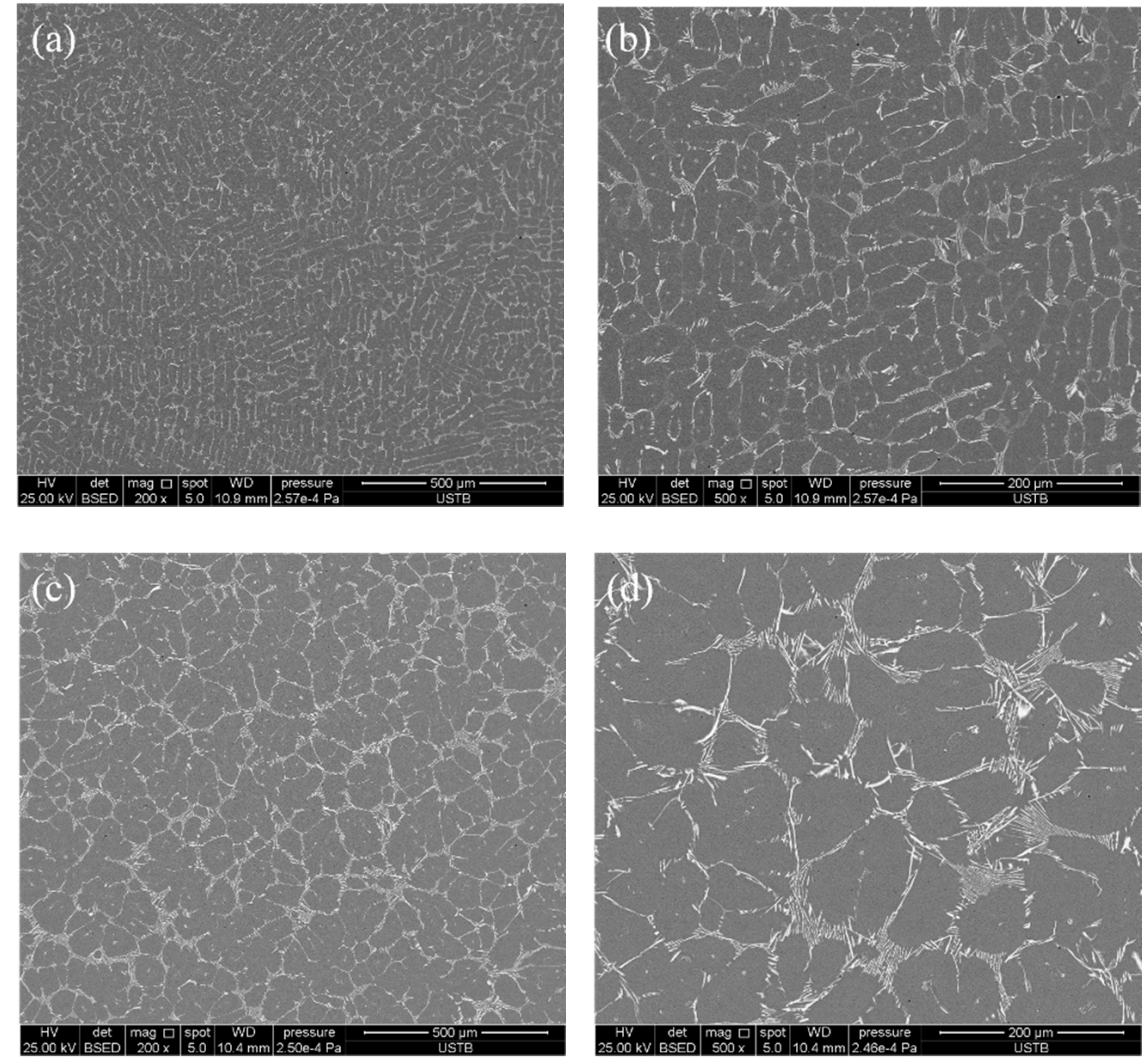

Figure 3. SEM images of HSS solidification structure: (a,b) As-cast ingot; (c,d) ESR ingot.

The morphology of MC carbide shown in Figure 4 was short rod-shaped, while $\mathrm{M}_{2} \mathrm{C}$ carbide was disc-shaped with multi-angles. MC carbides precipitated along pre-existed austenitic grain boundaries [20]. The morphology of MC carbide was influenced by local concentration of solute atoms and pre-formed austenite dendritic interface, as well as the solidification rate [21]. It can be confirmed from the EDS results in Figure 5 and XRD analysis in Figure 6 that $\mathrm{M}_{2} \mathrm{C}$ is $\mathrm{Mo}_{2} \mathrm{C}$ and $\mathrm{MC}$ is $\mathrm{VC}$. 

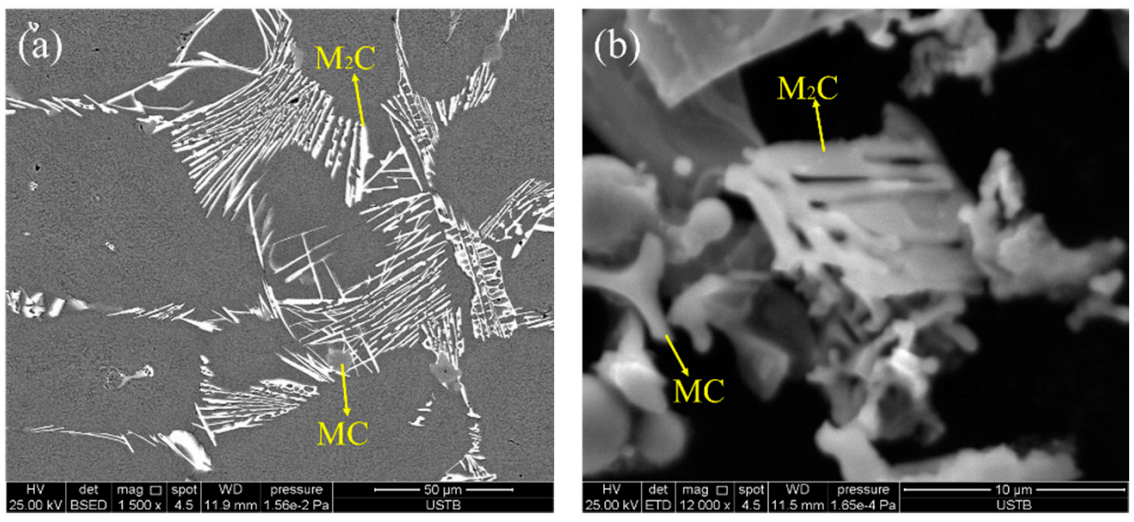

Figure 4. Two-dimensional morphology (a) and three-dimensional morphology (b) of carbides.
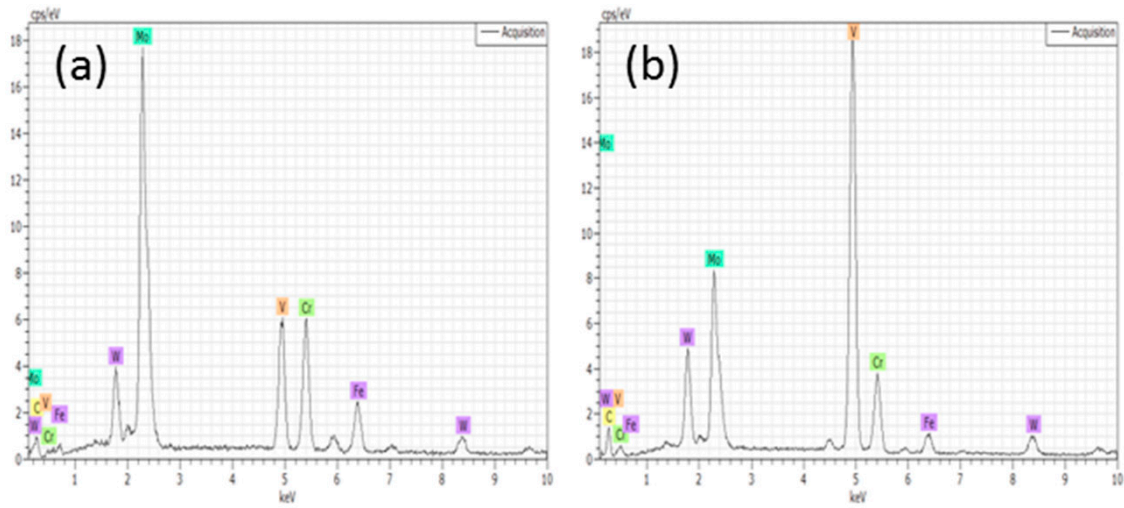

Figure 5. EDS analyzed results of $\mathrm{M}_{2} \mathrm{C}(\mathbf{a})$ and $\mathrm{MC}(\mathbf{b})$ carbides.

(a)

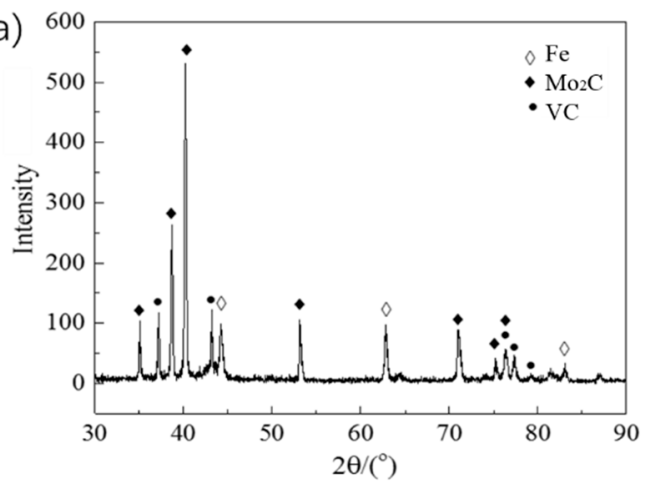

(b)

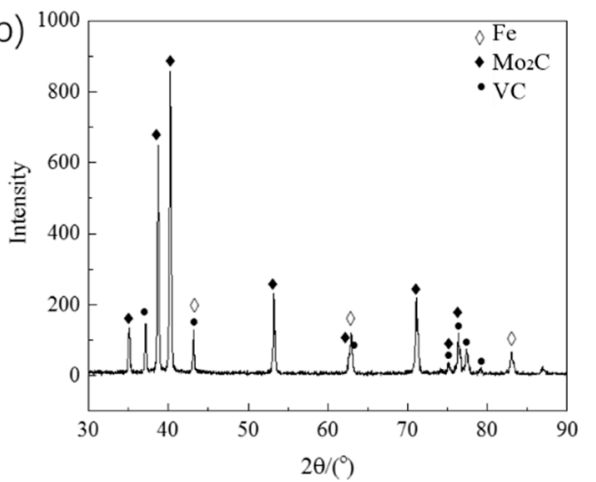

Figure 6. XRD pattern of HSS at different modes: (a) As-cast; (b) ESR.

\subsection{Phases Formation Calculated with Thermo-Calc Software}

The equilibrium formation of precipitates in the studied steel was investigated using Thermo-Calc software (TCFE7 database). As shown in Figure 7, five different types of carbides, i.e., $\mathrm{M}_{6} \mathrm{C}, \mathrm{MC}, \mathrm{M}_{2} \mathrm{C}, \mathrm{M}_{7} \mathrm{C}_{3}$, and $\mathrm{M}_{23} \mathrm{C}_{6}$, precipitated in sequence with decreasing temperature, in high-speed steel under the conditions of equilibrium solidification and cooling. (M represents metallic element atom, $\mathrm{C}$ represents carbon atom.) The transformation (precipitation) temperature of precipitates in the investigated steel are listed in Table 3. The temperature of precipitated $\mathrm{M}_{6} \mathrm{C}, \mathrm{MC}, \mathrm{M}_{2} \mathrm{C}, \mathrm{M}_{7} \mathrm{C}_{3}$, and $\mathrm{M}_{23} \mathrm{C}_{6}$ in sequence during equilibrium solidification condition were $1290{ }^{\circ} \mathrm{C}, 1250{ }^{\circ} \mathrm{C}, 1000{ }^{\circ} \mathrm{C}, 826^{\circ} \mathrm{C}$, and $824^{\circ} \mathrm{C}$, respectively. 


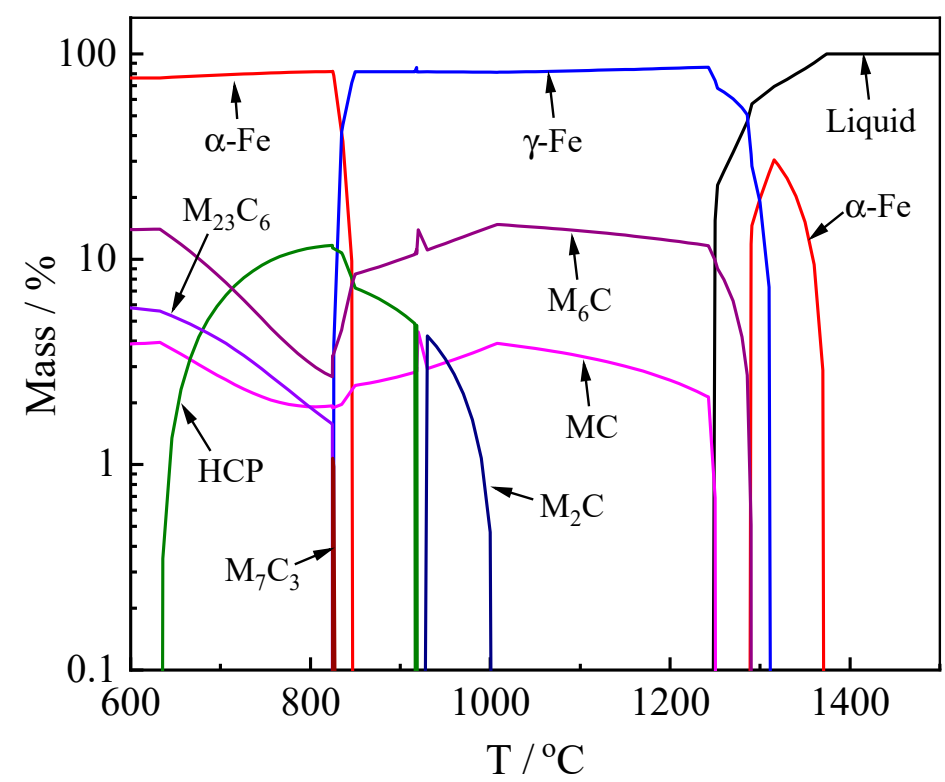

Figure 7. The phase equilibrium and transformation during solidification of liquid steel.

Table 3. Transformation temperature of precipitates in steel, calculated by Thermo-Calc.

\begin{tabular}{ccccccc}
\hline & \multicolumn{3}{c}{$\mathrm{T}_{\mathbf{s}} /{ }^{\circ} \mathbf{C}$} & \multicolumn{3}{c}{$\mathrm{T}_{\mathbf{f}} /{ }^{\circ} \mathbf{C}$} \\
\hline $\mathrm{M}_{6} \mathrm{C}$ & $\mathrm{MC}$ & $\mathrm{M}_{2} \mathrm{C}$ & $\mathrm{M}_{7} \mathrm{C}_{3}$ & $\mathrm{M}_{23} \mathrm{C}_{6}$ & $\mathrm{M}_{2} \mathrm{C}$ & $\mathrm{M}_{7} \mathrm{C}_{3}$ \\
1290 & 1250 & 1000 & 826 & 824 & 920 & 824 \\
\hline \multicolumn{2}{r}{ T represents phase transformation starting temperature; $\mathrm{T}_{\mathrm{f}}$ represents phase transformation finish temperature. }
\end{tabular}

In practical solidification process, the carbides forming elements with solute partition coefficients (k) smaller than 1 would segregate at the solid/liquid interface, which would lead to eutectic reaction in the inter-dendritic regions [19]. To predict phase precipitation during liquid steel solidification in a practical ESR refining process, the Scheil-Gulliver model included in Thermo-Calc software was employed to calculate the non-equilibrium phase precipitation in high speed steel, as shown in Figure 8. MC, $M_{6} C, M_{2} C$, and $M_{7} C_{3}$ carbides precipitated from liquid steel directly in non-equilibrium condition; reactions, phase transformation starting time, and solid fraction are listed in Table 4 . However, $\mathrm{M}_{6} \mathrm{C}$ and $\mathrm{M}_{7} \mathrm{C}_{3}$ carbides cannot be found in microstructure, which may be attributed to rapid solidification resulting to precipitation of carbides from austenite phase scarcely [22]. Thus, the microstructure consists of austenite, eutectic $\mathrm{Mo}_{2} \mathrm{C}$, and VC carbides.

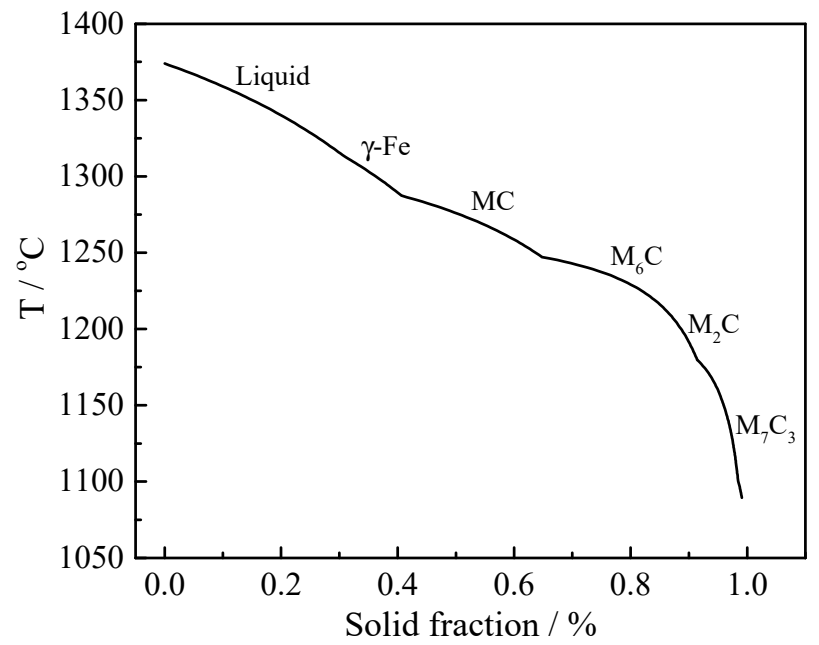

Figure 8. Non-equilibrium phase diagram in HSS. 
Table 4. Calculation results of non-equilibrium phase precipitation using Thermo-Calc.

\begin{tabular}{ccc}
\hline Reaction & $\mathbf{T}_{\mathbf{s}} /{ }^{\circ} \mathbf{C}$ & $\mathbf{f}_{\mathbf{s}}$ \\
\hline $\mathrm{L} \rightarrow \gamma-\mathrm{Fe}+\mathrm{MC}$ & 1287 & 0.4 \\
$\mathrm{~L} \rightarrow \gamma-\mathrm{Fe}+\mathrm{MC}+\mathrm{M}_{6} \mathrm{C}$ & 1245 & 0.65 \\
$\mathrm{~L} \rightarrow \gamma-\mathrm{Fe}+\mathrm{MC}+\mathrm{M}_{6} \mathrm{C}+\mathrm{M}_{2} \mathrm{C}$ & 1219 & 0.84 \\
$\mathrm{~L} \rightarrow \gamma-\mathrm{Fe}+\mathrm{MC}+\mathrm{M}_{6} \mathrm{C}+\mathrm{M}_{2} \mathrm{C}+\mathrm{M}_{7} \mathrm{C}_{3}$ & 1180 & 0.9 \\
\hline
\end{tabular}

$\mathrm{T}_{\mathrm{S}}$ represents phase transformation starting temperature; $\mathrm{f}_{\mathrm{s}}$ represents solid fraction of liquid steel.

\subsection{Effect of Heat Treatment on Carbide Evolution}

The microstructure of forging and hot rolling HSS are shown in Figure 9. When the ESR ingot was forged, the grain was stretched and refined. Most of the grain size was between 10-20 $\mu \mathrm{m}$ and the grain was in lath shape. The carbides network near the grain boundary was broken and distributed in a certain direction under the action of forging pressure. Fibrous $\mathrm{M}_{2} \mathrm{C}$ carbides were completely decomposed. $\mathrm{M}_{6} \mathrm{C}$ carbides were also broken, and became ellipsoidal finer carbides. However, the carbides were not completely disconnected from each other. The shape and size of MC carbides do not change significantly. After hot rolling, the microstructure of HSS had been further refined, the grains were deformed. The carbides were almost completely spherical and were broken into smaller individual particles dispersed in the matrix. The carbide size was basically below $5 \mu \mathrm{m}$ and the distribution of carbides was homogeneous. There were a lot of dispersed fine carbides in the matrix and the size was $1 \mu \mathrm{m}$ or even smaller, which strengthened the matrix.
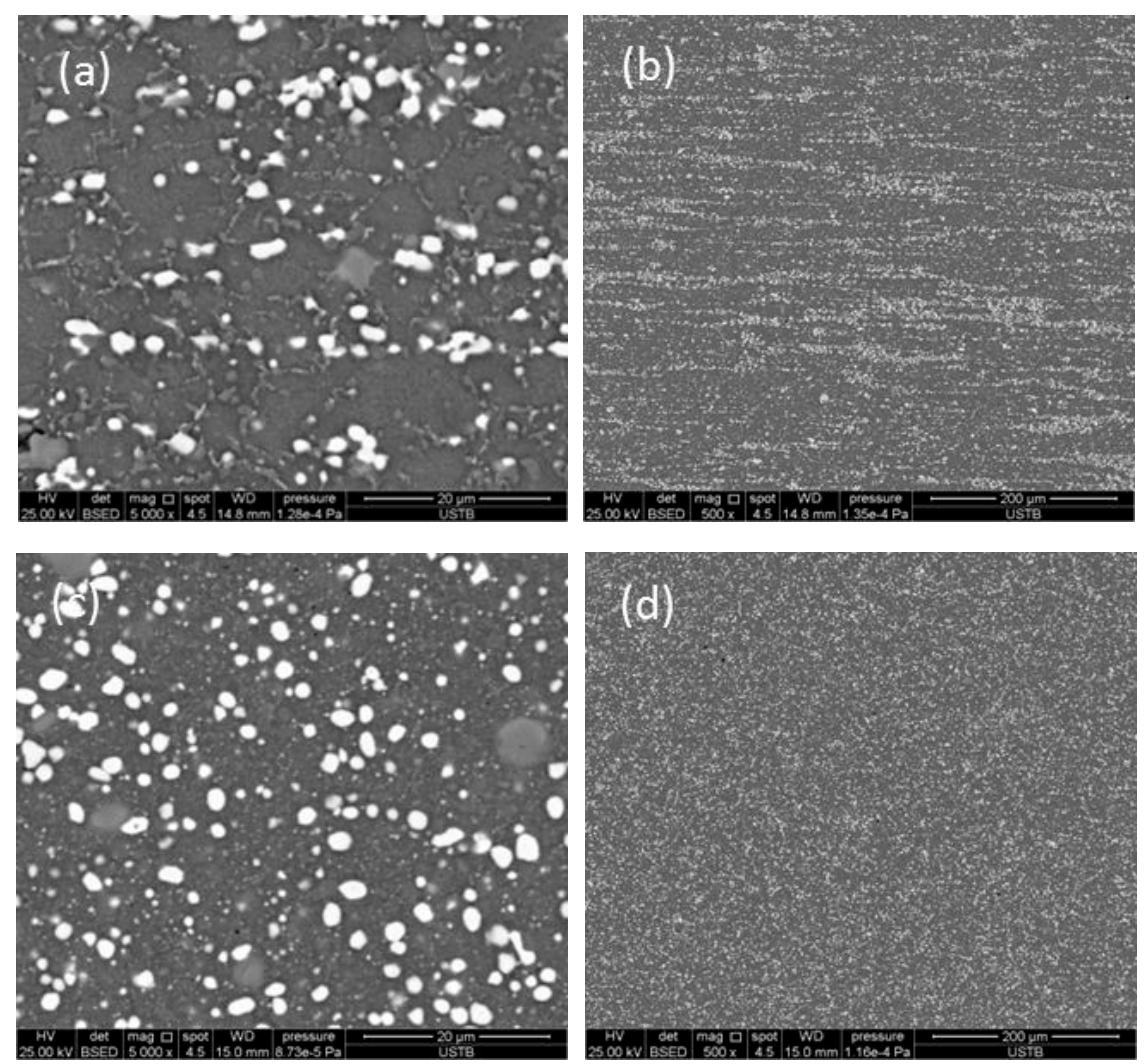

Figure 9. The microstructure of HSS after forging $(\mathbf{a}, \mathbf{b})$ and hot rolling $(\mathbf{c}, \mathbf{d})$.

Figure 10 shows the XRD pattern of HSS after solution treatment, and the effect of solution treatment temperature and solution treatment time on microstructure and carbide evolution are shown in Figure 11. $\mathrm{M}_{2} \mathrm{C}$ is easy to decompose upon heating and decomposed into stable carbides through $\mathrm{M}_{2} \mathrm{C}+\gamma-\mathrm{Fe} \rightarrow \mathrm{M}_{6} \mathrm{C}+\mathrm{MC}$ and $\mathrm{M}_{2} \mathrm{C}+\gamma-\mathrm{Fe} \rightarrow \mathrm{M}_{6} \mathrm{C}+\mathrm{M}_{7} \mathrm{C}_{3}$ $+\mathrm{MC}$ [23]. Therefore, there were retained lamellar $\mathrm{Mo}_{2} \mathrm{C}$, white rod-like $\mathrm{Fe}_{2} \mathrm{Mo}_{4} \mathrm{C}$ and 
grey spherical VC as shown in Figure 11. $\mathrm{Cr}_{7} \mathrm{C}_{3}$ carbides were fine granular shape, which was hard to find in the microstructure. With the solution treatment time increasing, the disconnection of carbides was gradually obvious, while the layers of $\mathrm{Mo}_{2} \mathrm{C}$ were also bent and deformed and partial carbides were spheroidized. When solution treatment time was at $4 \mathrm{~h}$, most of the carbides have been spheroidized and transformed into blocks or spheres. The size of the carbides was reduced, and the distribution of the carbides was more homogeneous. Due to the continuous diffusion of alloying elements, the partial carbides have aggregated and grown, but the network structure of carbides still existed. The decomposition rate of $\mathrm{M}_{2} \mathrm{C}$ carbide was the fastest at $1100{ }^{\circ} \mathrm{C}$ [23]. Compared with the carbide size and distribution of solution treatment temperature at $1130{ }^{\circ} \mathrm{C}$, solution treatment effect was better at the solution treatment temperature of $1080^{\circ} \mathrm{C}$.

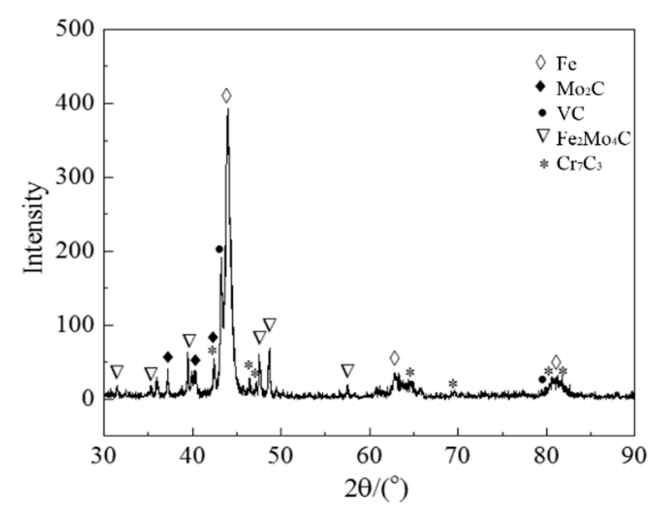

Figure 10. XRD pattern of HSS after solution treatment.
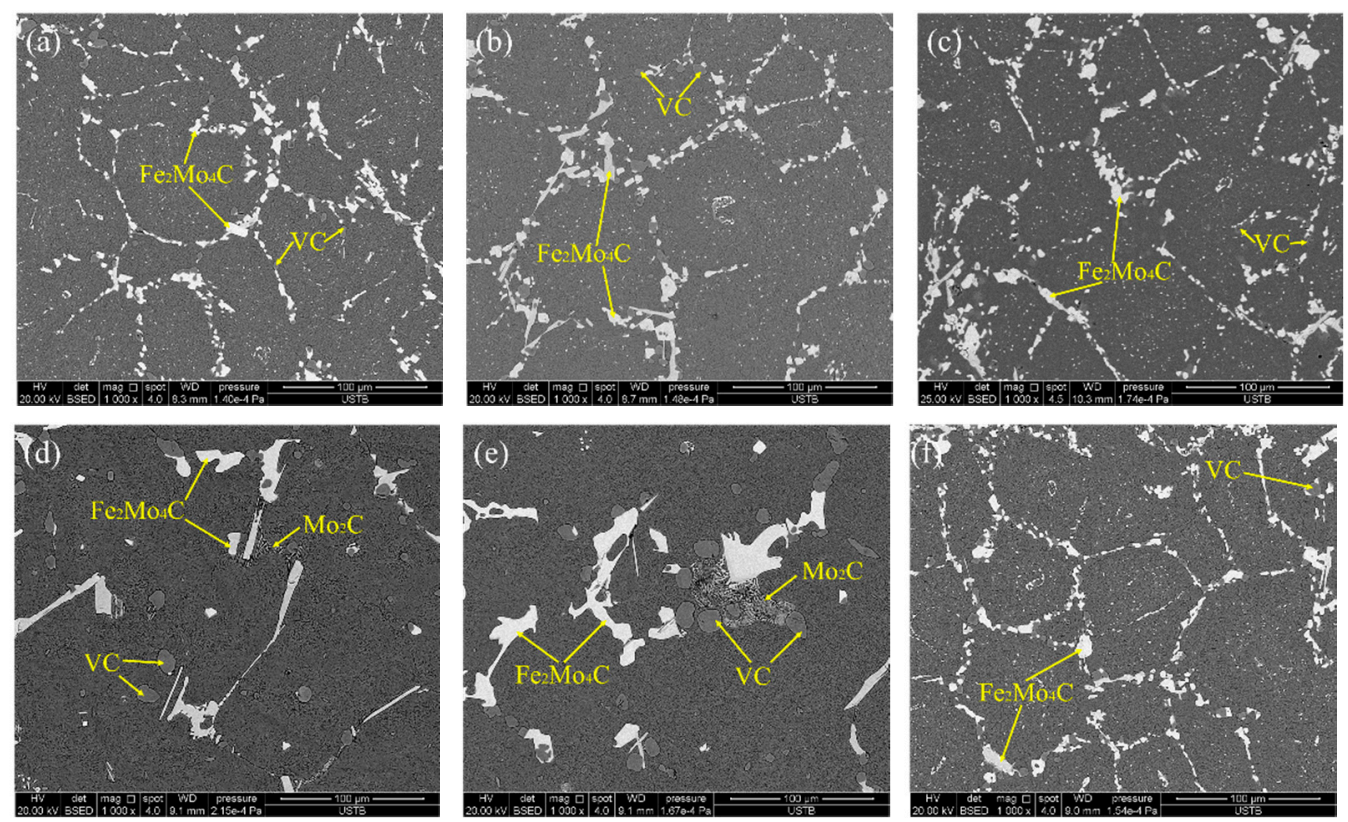

Figure 11. Effect of solution treatment temperature and solution treatment time on microstructure and carbide evolution: (a) 1080-1; (b) 1080-2; (c) 1080-4; (d) 1130-1; (e) 1130-2; (f) 1130-4.

Carbides solubility product in austenite can be calculated as follows [24]:

$$
\begin{gathered}
\ln [\mathrm{w}([\mathrm{V}]) \cdot \mathrm{w}([\mathrm{C}])]=9.59-\frac{14,828}{T} \\
\ln \left[\mathrm{w}([C r])^{7} \cdot \mathrm{w}([\mathrm{C}])^{3}\right]=50.76-\frac{51,516}{T}
\end{gathered}
$$




$$
\ln \left[\mathrm{w}([\mathrm{Mo}])^{2} \cdot \mathrm{w}([\mathrm{C}])\right]=17.35-\frac{17,788}{T}
$$

The relationship of equilibrium solubility product and actual solubility product was shown in Equation (4). $Q_{M_{x} N_{y}}^{\varnothing}$ is equilibrium solubility product and $Q_{M_{x} N_{y}}$ is actual solubility product. When $\triangle \mathrm{G}<0$, which means $Q_{M_{x} N_{y}}^{\varnothing}<Q_{M_{x} N_{y}}$, the reaction proceeds in the direction of the formation of precipitates. The solubility product of carbides precipitated from the solid phase during the solidification process is shown in Figure 12. Both VC and $\mathrm{Mo}_{2} \mathrm{C}$ can be precipitated from the solid phase when the cooling progresses to the solid phase temperature. However, $\mathrm{Cr}_{7} \mathrm{C}_{3}$ begins to precipitate when the temperature drops to $1115 \mathrm{~K}\left(842{ }^{\circ} \mathrm{C}\right)$, which is lower than the solution treatment temperature [24]. Due to the precipitation temperature being low, the time for nucleation and growth is short, $\mathrm{Cr}_{7} \mathrm{C}_{3}$ carbides exist in the steel in the form of small particles. When the cooling rate is fast, they will not be precipitated.

$$
\Delta G=\Delta G^{\theta}+R T \ln \frac{1}{Q_{M_{x} N_{y}}}=R T \ln \frac{Q_{M_{x} N_{y}}^{\varnothing}}{Q_{M_{x} N_{y}}}
$$

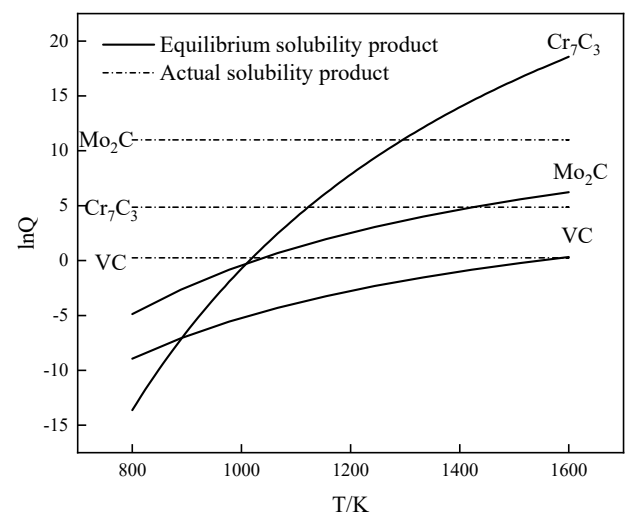

Figure 12. Curves of equilibrium solubility product and actual solubility product to temperature of solid HSS.

The basic parameters and microstructure characteristic parameters of carbides were calculated and analyzed by image analysis software. The characteristic parameters include the volume fraction of carbide $V_{V}$, the number of carbides per unit volume $N_{V}$, the average diameter of carbides $\bar{D}$, and the distance between carbides $t_{0}$. The relation between them is shown in detail in Table $5 . \mathrm{A}_{\mathrm{A}}$ is the area fraction of carbide, and $\mathrm{N}_{\mathrm{A}}$ is the total number of carbides in the area. In this study, the following parameters could be obtained by software: the number of carbides $\mathrm{N}_{\mathrm{A}}$, the area of carbides $\mathrm{A}$, the average diameter of carbides $D$, as shown in Table 6. The characteristic parameter of all kinds of carbides in the steel can be calculated based on the microstructure characteristic parameters in Table 5 and the basic parameter values in Table 6. The calculated results are also shown in Table 6.

Table 5. The basic relation between the microstructure characteristic parameters.

\begin{tabular}{ccc}
\hline Relation Formula & Unit & Spatial Characteristic Parameter \\
\hline $\mathrm{V}_{\mathrm{V}}=\mathrm{A}_{\mathrm{A}}$ & $\%$ & Volume fraction of carbide \\
$\mathrm{N}_{\mathrm{V}}=\mathrm{N}_{\mathrm{A}} / \bar{D}$ & - & Number of carbides in per unit volume \\
$\mathrm{t}_{0}=\sqrt[3]{1 / \mathrm{N}_{\mathrm{V}}}$ & $\mu \mathrm{m}$ & Space distance of carbide \\
\hline
\end{tabular}


Table 6. Basic parameters and characteristic parameters of carbides.

\begin{tabular}{ccccccc}
\hline \multirow{2}{*}{ Status } & \multicolumn{3}{c}{ Basic Parameters } & \multicolumn{3}{c}{ Characteristic Parameters } \\
\cline { 2 - 6 } & $\mathbf{N}_{\mathbf{A}}$ & $\mathbf{A} / \mathbf{\mu m}^{\mathbf{2}}$ & $\bar{D} / \boldsymbol{\mu} \mathbf{m}$ & $\mathbf{V} \mathbf{V} / \mathbf{o}$ & $\mathbf{N}_{\mathbf{V}}$ & $\mathbf{t}_{\mathbf{0}} / \boldsymbol{\mu \mathbf { m }}$ \\
\hline ESR & 1671 & 5491 & 3.84 & 7.06 & $5.60 \times 10^{-3}$ & 13.37 \\
Hot-rolling & 2334 & 1817 & 1.28 & 9.54 & $9.57 \times 10^{-2}$ & 3.23 \\
Solution treatment & 522 & 7706 & 5.03 & 9.90 & $1.33 \times 10^{-3}$ & 27.39 \\
\hline
\end{tabular}

Comparing the characteristic parameters of carbides in different process samples, it can be found that the amount of carbides decreased after the solution treatment, while the volume fraction increased. Comparison between Figures 3 and 11 shows that, the lamellar and fibrous $\mathrm{M}_{2} \mathrm{C}$ carbides were decomposed into $\mathrm{M}_{6} \mathrm{C}$ and $\mathrm{MC} . \mathrm{M}_{6} \mathrm{C}$ grew into short rod, resulting in the reduction of the amount of carbides and the slight addition of the carbides size. Although the volume fraction of carbides increased from $7.06 \%$ to $9.9 \%$, the number of carbide particles per unit volume decreased. The average diameters of carbides were 3.84 and 5.03, respectively, in the ESR sample and the solution treatment sample. After hot rolling, the average diameter of carbides has been reduced to $1.28 \mu \mathrm{m}$ and the volume fraction varies little, from $7.06 \%$ to $9.54 \%$. However, the carbides particle number increased a lot, from 1671 to 2334, and the distance between carbides particles was reduced from 13.37 to 3.23 . Therefore, the carbides in hot-rolled high-speed steel were more dispersed in the matrix.

\section{Conclusions}

1. The carbides of high-speed steel after electroslag remelting are of a large size and mainly lamellar and fibrous precipitates along the grain boundary. After solution treatment, the size of carbides is obviously reduced and the distribution of carbides are uniform, and the morphology of carbides are mainly short-rod, irregular spherical, and fine particles.

2. The carbide types both in as-cast and ESR high-speed steel are metastable carbides $\mathrm{Mo}_{2} \mathrm{C}$ and $\mathrm{VC}$. The types of carbides after solution treatment, forging, and hot rolling are mainly small composite carbides containing molybdenum, vanadium, and chromium, including $\mathrm{Mo}_{6} \mathrm{C}, \mathrm{VC}$, and $\mathrm{Cr}_{7} \mathrm{C}_{3} . \mathrm{Mo}_{2} \mathrm{C}$ carbides in $\mathrm{ESR}$ ingot can be decomposed into $\mathrm{VC}$ and $\mathrm{Fe}_{2} \mathrm{Mo}_{4} \mathrm{C}$ during the solution treatment.

3. After forging and hot rolling, carbides are completely spheroidal and dispersed in the matrix. The average diameter of the carbides can be reduced to $1.28 \mu \mathrm{m}$ and the space distance reduced to $3.23 \mu \mathrm{m}$. A uniform distribution of spheroidal shaped carbides was achieved.

Author Contributions: Y.L. and J.L. conceived and designed the experiments; Y.Q. and J.G. performed the experiments; Y.L. and W.L. analyzed the data; J.L. contributed reagents/materials/analysis tools; Y.L. wrote the paper; Y.L., W.L. and C.S. revised the paper. All authors have read and agreed to the published version of the manuscript.

Funding: This research was funded by the National Natural Science Foundation of China (NSFC), grant number 51874030 and Science and Technology Project of Guangdong Province, grant number SDZX2021002.

Data Availability Statement: Not applicable.

Conflicts of Interest: The authors declare no conflict of interest.

\section{References}

1. Sano, Y.; Hattori, T.; Haga, M. Characteristics of high-carbon high speed steel rolls for hot strip mill. ISIJ Int. 1992, 32, $1194-1201$. [CrossRef]

2. Chu, W.; Xie, C.; Wu, X.C. Research on controlling eutectic carbides in M2 high speed steel of ESR process. Shanghai Met. 2013, 25, 23-26+62. (In Chinese) 
3. Zhou, X.F.; Fang, F.; Li, F.; Jiang, J.Q. Morphology and microstructure of $\mathrm{M}_{2} \mathrm{C}$ carbide formed at different cooling rates in AIST M2 high speed steel. J. Mater. Sci. 2011, 46, 1196-1202. [CrossRef]

4. Mattar, T.; Ibrahim, K.M.; Fathy, A.; Faramawy, H.E. Improving the wear resistance of M41 steel by nitrogen alloying and ESR. Mater. Charact. 2007, 58, 407-415. [CrossRef]

5. Kim, C.K.; Park, J.I.; Lee, S.; Kim, Y.C.; Yang, N.J. Effects of alloying elements on microstructure, hardness, and fracture toughness of centrifugally cast high-speed steel rolls. Metall. Mater. Trams. A 2005, 36, 87-97. [CrossRef]

6. $\quad$ Deng, Y.K.; Chen, J.R.; Wang, S.Z. High Speed Tool Steel; Guo, G.C., Ed.; Metallurgical Industry Press: Beijing, China, 2002; pp. 199-200.

7. Zhou, X.F.; Zhu, W.L.; Jiang, H.B.; Fang, F.; Tu, Y.Y.; Jiang, J.Q. A new approach for refining carbide dimensions in M42 super hard high-speed steel. J. Iron Steel Res. Int. 2016, 23, 800-807. [CrossRef]

8. Rodenburg, C.; Rainforth, W.M. A quantitative analysis of the influence of carbides size distributions on wear behavior of high-speed steel in dry rolling/sliding contact. Acta Mater. 2007, 55, 2443-2454. [CrossRef]

9. Zhu, Q.; Zhu, H.T.; Tieu, A.K.; Reid, M.; Zhang, L.C. In-situ investigation of oxidation behavior in high-speed steel roll material under dry and humid atmospheres. Corros. Sci. 2010, 52, 2707-2715. [CrossRef]

10. Gill, S.S.; Singh, J.; Singh, R.; Singh, H. Effect of cryogenic treatment on AIST M2 high speed steel: Metallurgical and mechanical characterization. J. Mater. Eng. Perform. 2012, 21, 1320-1326. [CrossRef]

11. Kou, G.F.; Yan, X.G.; Liang, Y.; Li, J.J.; Chen, Y.H.; Fu, J.W.; Cao, Q.C. Effect of cryogenic temperature on abrasion performance of W6Mo5Cr4V2 high speed steel. Trans. Mater. Heat Treat. 2016, 37, 39-43. (In Chinese)

12. Lei, L.J.; Jia, F.; Qin, C. Origin of square segregation in high speed steel tool steel bars in electroslag refining. Heibei Metall. 1998, Z1, 52-54+143. (In Chinese)

13. Shi, C.B.; Chen, X.C.; Guo, H.J.; Zhu, Z.J.; Sun, X.L. Control of $\mathrm{MgO} \cdot \mathrm{Al}_{2} \mathrm{O}_{3}$ spinel inclusions during protective gas electroslag remelting of die steel. Metall. Mater. Trans. B 2013, 44, 378-389. [CrossRef]

14. Shu, S.H.; Choi, J. Effect of melting rate on the carbide cell size in an electroslag remelted high speed steel ingot. ISIJ Int. 1986, 26, 305-309.

15. Ma, D.X.; Grafe, U. Microstructure in directionally solidified dendritic-cellular structure of superalloy CMSX-4. Mater. Sci. Eng. A 1999, 2, 339-342. [CrossRef]

16. Lenta, E.J.; Twentyman, M.E.; Pesci, H. Transformation of the primary carbide networks in high-speed steels by heat treatment at high temperatures. Metallography 1983, 16, 387-401. [CrossRef]

17. Fu, R.; Li, F.L.; Yin, F.J.; Feng, D.; Tian, Z.L.; Chang, L.T. Microstructure evolution and deformation mechanisms of the electroslag refined-continuous directionally solidified (ESR-CDS) superalloy Rene88DT during isothermal compression. Mater. Sci. Eng. A 2015, 638, 152-164. [CrossRef]

18. Zhou, X.F.; Fang, F.; Li, F.; Jiang, J.Q. Study on property and morphology of $\mathrm{M}_{2} \mathrm{C}$ eutectic carbides in M2 high speed steel. Iron Steel 2009, 9, 76-80. (In Chinese)

19. Qi, Y.F.; Li, J.; Shi, C.B.; Zhang, Y.; Zhu, Q.T.; Wang, H. Effect of directional solidification of electroslag remelting on the microstructure and primary carbides in an austenitic hot-work die steel. J. Mater. Process. Technol. 2017, 249, 32-38. [CrossRef]

20. Li, X.W.; Wang, L.; Dong, J.S.; Lou, L.H. Effect of solidification condition and carbon content on the morphology of MC carbide in directional solidified Nickel-base superalloys. J. Mater. Sci. Technol. 2014, 30, 1296-1300. [CrossRef]

21. Qi, Y.F.; Li, J.; Shi, C.B. Characterization on microstructure and carbides in an austenitic hot-work die steel during ESR solidification process. ISIJ Int. 2018, 58, 2079-2087. [CrossRef]

22. Halfa, H.; Eissa, M.; EI-Fawakhry, K.; Mattar, T. Effect of nitrogen and niobium on the structure and secondary hardening of super hard high speed tool steel. Steel Res. Int. 2012, 83, 32-42. [CrossRef]

23. Lee, E.S.; Park, W.J.; Jung, J.Y.; Ahn, S. Solidification microstructure and $\mathrm{M}_{2} \mathrm{C}$ carbide decomposition in a spray-formed high-speed steel. Metal. Mater. Trans. A 1998, 29, 1395-1404. [CrossRef]

24. Luo, Y.W.; Guo, H.J.; Sun, X.L. Precipitation behaviors of carbides in M42 high speed steel during ESR and forging. Iron Steel 2017, 52, 68-75. (In Chinese) 